\title{
PENGARUH CURRENT RATIO DAN DEBT TO ASSETS RATIO TERHADAP NET PROFIT MARGIN PADA PT.NDO TAMBANG RAYA MEGAH TBK (PERIODE 2008-2017)
}

\author{
NINA SHABRINA \\ Email : dosen01567@unpam.ac.id
}

\begin{abstract}
ABSTRAK
Tujuan dari penelitian ini adalah untuk mengetahui pengaruh Current Ratio (CR) dan Debt to Assets Ratio (DAR) Terhadap Net Profit Margin (NPM) pada PT Indo Tambangraya Mega TBK Periode 2008-2017. Jenis penelitian ini menggunakan penelitian deskriptif, karena analisis tersebut mengemukakan uraian-uraian serta penjelasan dengan membandingkan data yang diperoleh dari penelitian dengan dasar-dasar teori yang ada kemudian hasilnya akan menjadi sebuah kesimpulan. Sampel yang digunakan dalam penelitian ini adalah berupa laporan keuangan pada PT Indo Tambangraya Megah TBK dari tahun 2008 sampai dengan 2017. Analisis data yang digunakan dalam penelitian ini adalah rasio keuangan, analisis regresi linier berganda, uji asumsi klasik, uji hipotesis, dan koefisien determinasi.

Hasil penelitian menunjukkan persamaan analisis regresi linier berganda yaitu $\mathrm{Y}=-69,189+$ $0,148 X 1+1,704 X 2$. Kemudian Koefisien Derteminasi yang diperoleh dari penelitian ini adalah sebesar 76,4\% dan sisanya 23,6\% dipengaruhi oleh variabel lain yang tidak diteliti di dalam penelitian ini. Dari hasil penelitian Pengaruh Current Ratio ( CR ) dan Debt to Assets Ratio ( DAR ) terhadap Net Profit Margin (NPM) diperoleh hasil nilai signifikasi sebesar $0,007 \square 0,05$ thitung lebih besar daripada ttabel atau sebesar 3,718 > 2,365 maka dapat disimpulkan bahwa adanya pengaruh positif dan signifikan antara Current Ratio (CR) terhadap Net Profit Margin (NPM). Kemudian hasil penelitian pengaruh Debt to Asset Ratio (DAR) terhadap Net Profit Margin (NPM) diperoleh hasil nilai signifikasi sebesar 0,003 $<0,05$ dan nilai thitung lebih besar daripada ttabel atau sebesar 4,489>2,365 maka dapat disimpulkan bahwa adanya pengaruh positif dan signifikan antara Debt to Asset Ratio (DAR) terhadap Net Profit Margin (NPM). Dan hasil penelitian pengaruh Current Ratio (CR) dan Debt to Assets Rasio (DAR) secara bersama-sama terhadap Net Profit Margin (NPM) diperoleh hasil nilai signifikansi sebesar 0,006 < 0,05 dan Fhitung lebih besar daripada Ftabel yaitu 11,343> 4,74 maka dapat disimpulkan bahwa Current Ratio (CR) dan Debt to Assets Ratio (DAR) secara bersamasama berpengaruh positif dan signifikan terhadap Net Profit Margin (NPM).
\end{abstract}

Kata kunci : Current Ratio (CR), Debt to Assets Ratio (DAR), Net Profit Margin (NPM).

\section{PENDAHULUAN}

A. Latar Belakang Masalah

Perkembangan dunia usaha saat ini sangat cepat, banyak munculnya usaha bisnis baru dengan persaingan yang ketat, baik sektor industrial maupun jasa semakin kritis dan tajam. Adanya perusahaan yang menjadi perusahaan go public dimana saham-sahamnya yang dahulu hanya dimiliki oleh pemegang saham tertentu saja. Indonesia sebagai salah satu Negara yang berkembang dengan memiliki ciri adanya pembangunan di segala bidang perekonomian dunia usaha. Sehingga 
semakin berkembangnya

kegiatan perekonomian, maka akan meningkat pertumbuhan suatu perusahaan.

Net Profit Margin pada PT Indo Tambang raya Megah TBK yang terdaftar di Bursa Efek Indonesia mengalami kecenderung berfluktuatif meningkat pada perubahan Net Profit Margin tiap tahunnya. Berikut ini adalah data rata-rata tahunan Current Ratio (CR) dan Debt to Assets Ratio (DAR) terhadap Net Profit Margin (NPM) pada PT Indo Tambangraya Megah TBK :

Tabel 1.1

Current Ratio (CR), Debt to Assets Ratio (DAR) dan Net Profit Margin (NPM) PT Indo Tambangraya Megah TBK Periode 2008-2017

\begin{tabular}{|l|l|l|l|}
\hline Tahun & $\begin{array}{l}\text { Current } \\
\text { Ratio (\%) }\end{array}$ & $\begin{array}{l}\text { Debt to } \\
\text { Assets } \\
\text { Ratio(\%) }\end{array}$ & $\begin{array}{l}\text { Net Profit } \\
\text { Margin } \\
(\%)\end{array}$ \\
\hline 2008 & 149.11 & 37.66 & 17.84 \\
\hline 2009 & 197.79 & 34.30 & 22.25 \\
\hline 2010 & 183.44 & 33.83 & 12.24 \\
\hline 2011 & 236.59 & 31.53 & 22.93 \\
\hline 2012 & 221.71 & 32.78 & 17.71 \\
\hline 2013 & 199.19 & 30.76 & 10.58 \\
\hline 2014 & 156.40 & 31.26 & 10.31 \\
\hline 2015 & 180.18 & 29.18 & 3.97 \\
\hline 2016 & 225.68 & 24.99 & 9.56 \\
\hline 2017 & 243.35 & 29.48 & 14.96 \\
\hline
\end{tabular}

Sumber: Data Diolah

Berdasarkan Tabel 1.1 di atas dapat diketahui bahwa Current Ratio (CR) dan Debt to Assets Ratio (DAR) terhadap Net Profit Margin (NPM)pada PT Indo Tambangraya Megah TBK mengalami kenaikan dan penurunan yang tidak konsisten disetiap tahunnya. Sehingga berdampak terhadap berapa besar tingkat Net Profit Margin (NPM).

Current Ratio (CR) pada PT Indo Tambangraya Megah TBK di tahun 2011 mengalami kenaikan sebesar 236,59\% tetapi pada tahun 2014 mengalami penurunan sebesar $156,40 \%$.

Debt to Assets Ratio pada PT Indo Tambangraya Megah TBK mengalami penurunan di tahun 2016 sebesar 24,99\% dan mengalami penaikan kembali di tahun 2017 sebesar 29,48\%. Sedangkan Net Profit Margin (NPM) di tahun 2015 mengalami penurunan yang drastis sebesar 3,97\%.

\section{TINJAUAN PUSTAKA}

A. Current Ratio (CR)

1. Pengertian Rasio Lancar (Current Ratio)

Menurut Kasmir (2015:134)

"Rasio Lancar (Current ratio) merupakan rasio untuk mengukur kemampuan perusahaan dalam membayar kewajiban jangka pendek atau utang yang segera jatuh tempo pada saat ditagih secara keseluruhan”.

\section{Tujuan Current Ratio}

"Menurut Kasmir (2012:132), menghasilkan beberapa tujuan antara lain : untuk mengukur kemampuan perusahaan membayar kewajiban jangka pendek dengan aktiva lancar secara keseluruhan dan untuk melihat kelemahan yang dimiliki perusahaan, yang ada di aktiva lancar dan hutang lancer."

\section{B. Debt to Assets Ratio (DAR)}

\section{Pengertian Debt to Assets Ratio}

Menurut Hery (2016:166) Debt to Assets Ratio merupakan rasio yang digunakan untuk mengukur perbandingan antara total utang dengan total asset”.

\section{Tujuan Debt to Assets Ratio}

a. Untuk mengetahui posisi perusahaan terhadap kewajiban kepada pihak lainnya (kreditor),

b. Untuk menilai kemampuan perusahaan dalam memenuhi 
kewajiban yang bersifat tetap (seperti angsuran pinjaman termasuk bunga),Untuk menilai keseimbangan antara nilai aktiva khususnya aktiva tetap dengan modal.

\section{Net Profit Margin(NPM)}

\section{Pengertian Net Profit Margin}

"Menurut Kasmir (2015:200) Net

Profit Margin merupakan ukuran keuntungan dengan membandingkan antara laba setelah bunga dan pajak dibandingkan dengan penjualan. Rasio ini menunjukkan pendapatan bersih perusahaan atas penjualan".

\section{Tujuan Net Profit Margin}

a. Untuk mengukur dan menghitung laba yang diperoleh perusahaan dalam satu periode tertentu (laba bersih setelah pajak),

b. Untuk menilai posisi laba perusahaan tahun sebelumnya dengan tahun sekarang,

c. Untuk menilai perkembangan laba dari waktu ke waktu.

\section{Kerangka Berpikir}

Adapun kerangka berpikir dalam penelitian ini adalah sebagai berikut :

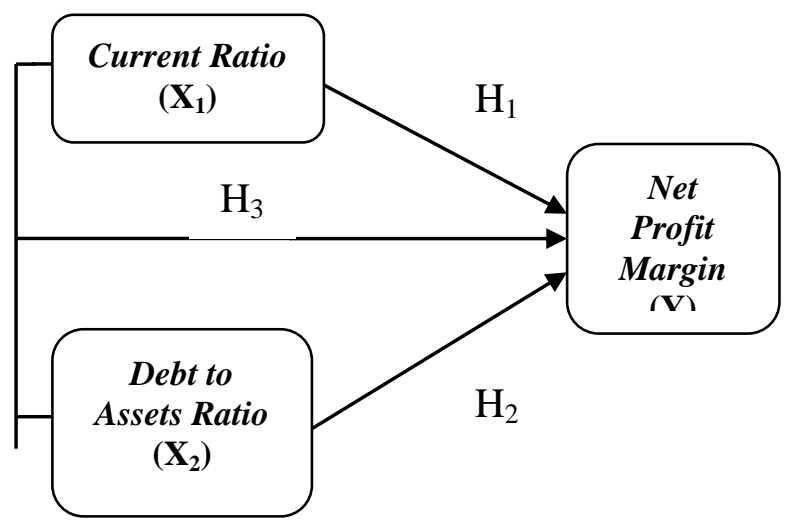

Gambar 2.1

Kerangka Berpikir

\section{METODOLOGI PENELITIAN}

\section{A. Metode Analisis Data}

Metode analisis data yang digunakan dalam penelitian ini sebagai berikut :

1. Rumus Manajeman Keuangan
a. Current Ratio
b. Debt to Assets Ratio
c. Net Profit Margin

2. Uji Statistik Deskriptif

"Menurut Widodo (2017:76)

Statistik deskriptif adalah teknik analisis data yang digunakan untuk menggambarkan kondisi variabel peneliti.Analisis deskriptif dapat disajikan dalam bentuk skor minimum, skor maksimum, jangkauan (range), mean, median,modus, standar devisiasi dan variannya serta dilengkapi dengan tabel distribusi frekuensi berikut histogramnya. Selain itu dapat pula disajikan dalam bentuk nilai rata-rata per item dan total (keseluruhan item)".

\section{Uji Asumsi Klasik}

Dalam penggunaan analisis korelasi agar menunjukkan hubungan yang valid atau tidak biasa maka perlu pengujian asumsi klasik pada model regresi yang digunakan. Asumsi dasar yang harus dipenuhi antara lain:

a. Uji Normalitas

Untuk mengetahui apakah disribusi sebuah data mengikuti atau mendekati normal perlu dilakukan uji normalitas. Pengujian menggunakan uji KolmogorovSmirnov (Analisis Explore) untuk mengetahui apakah distribusi data pada tiap-tiap variabel normal atau tidak. Kriteria pengambilan keputusan yaitu jika signifikansi > 0,05 maka data berdistribusi normal, dan jika signifikansi $<0,05$ maka data tidak berdistribusi normal.

b. Uji Multikolinearitas

Menurut Duwi Priyanto (2013:59)"multikolinearitas adalah keadaan dimana antar dua variabel independen atau lebih pada model regresi terjadi hubungan linier yang 
sempurna atau mendekati sempurna. Model regresi yang baik mensyaratkan tidak adanya masalah multikolinearitas. Metode untuk menguji adanya multikolinearitas dapat dilihat dari nilai tolerance dan variance inflation faktor (VIF)". Adapun dasar pengambilan keputusan sebagai berikut :

1) Jika nilai VIF < 10 maka tidak terjadi gejala multikolinearitas di antara variabel bebas.

2) Jika nilai VIF > 10 maka terjadi gejala multikolinearitas di antara variabel bebas.

c. Uji Heteroskedastisitas

Uji heteroskedastisitas digunakan untuk mengetahui adanya perbedaan varians dari suatu pengamatan ke pengamatan yang lain. Model regresi yang baik mensyaratkan tidak adanya masalah heteroskedastisitas.

d. Uji Autokorelasi

Autokorelasi bertujuan untuk menguji apakah didalam sebuah model regresi linear ada korelasi antara kesalahan pengganggu pada periode $\mathrm{t}$ dengan kesalahan periode $\mathrm{t}-1$ (sebelumnya), auto ini timbul pada data yang bersifat time series.

Model regresi yang baik mensyaratkan tidak adanya masalah autokorelasi yaitu varian sampel tidak dapat menggambarkan varian populasinya. Salah satu pengujian yang digunakan untuk mengetahui autokorelasi adalah uji Run Test. Dimana analisis Run Test termasuk dalam statistik non-parametik.

Menurut

Sugiyono (2017:112) Uji ini digunakan untuk menguji hipotesis deskriptif (satu sampel), bila skala pengukurannya ordinal maka Run Test dapat digunakan untuk mengukur urutan suatu kejadian. Pengujian dilakukan dengan cara mengukur kerandoman populasi yang didasarkan atas data hasil pengamatan melalui data sampel.

4. Analisis Regresi Linier Berganda

Analisis regresi linier berganda

Dalam penelitian ini yang menjadi variabel dependen adalah Net Profit Margin, sedangkan yang menjadi variabel independen adalah Current Ratio $\left(\mathrm{X}_{1}\right)$ dan Debt to Assets Ratio $\left(\mathrm{X}_{2}\right)$, sehingga persamaan regresi yang terbentuk adalah sebagai berikut:

$\mathbf{Y}=\mathbf{a}+\mathbf{b}_{1} \mathbf{X}_{1}+\mathbf{b}_{2} \mathbf{X}_{\mathbf{2}}$

Dimana :

$\mathrm{Y}=$ Variabel terikat (dependen)

$\mathrm{X}_{(1,2)}=$ Variabel bebas (independen)

$\mathrm{b}_{(1,2)}=$ Nilai koefisien regresi

$\mathrm{a}=$ Nilai konstanta

\section{Koefisien Korelasi}

Menurut Sofyan Siregar (2014:251) koefisien korelasi adalah bilangan yang menyatakan kekuatan hubungan antara dua variabel atau lebih atau juga dapat menentukan arah dari kedua variabel.

Tabel 3.1

Interpretasi Koefisien Korelasi

\begin{tabular}{|l|l|}
\hline $\begin{array}{l}\text { Interval } \\
\text { Koefisien }\end{array}$ & $\begin{array}{l}\text { Tingkat } \\
\text { Hubungan }\end{array}$ \\
\hline $0,00-0,199$ & Sangat Rendah \\
\hline $0,20-0,399$ & Rendah \\
\hline $0,40-0,599$ & Sedang \\
\hline $0,60-0,799$ & Kuat \\
\hline $0,80-1,000$ & Sangat Kuat \\
\hline
\end{tabular}

Sumber : Sugiyono (2015:54)

6. Uji Hipotesis

a. Uji Parsial (Uji T)

"Menurut Duwi Priyatno (2012:120) uji $t$ atau uji parsial digunakan untuk mengetahui apakah variabel independen secara parsial berpengaruh terhadap variabel dependen. Untuk menguji pengaruh variabel bebas secara parsial terhadap variabel terikat digunakan pengujian koefisien regresi secara parsial (uji t), yaitu 
dengan membandingkan $t_{\text {hitung }}$ dan $\mathrm{t}_{\text {tabel}}$.

Kriteria yang digunakan sebagai dasar perbandingan adalah sebagai berikut :

1. Uji hipotesis secara parsial menggunakan uji pihak kiri, dengan kriteria :

Ho diterima bila $t_{\text {hitung }} \geq t_{\text {tabel }}$ atau nilai sig $>0,05$

Ho ditolak bila $t_{\text {hitung }}<-t_{\text {tabel }}$ atau nilai sig $<0,05$

2. Uji hipotesis secara parsial menggunakan uji pihak kanan, dengan kriteria :

Ho diterima bila $t_{\text {hitung }} \leq t_{\text {tabel }}$ atau nilai sig $>0,05$

Ho ditolak bila $t_{\text {hitung }}>t_{\text {tabel }}$ atau nilai sig $<0,05$

Bila terjadi penerimaan Ho maka dapat disimpulkan suatu pengaruh adalah tidak signifikan, sedangkan bila Ho ditolak artinya suatu pengaruh adalah signifikan.

\section{b. Uji Simultan (Uji F)}

Uji simultan ini (Uji F) ini bertujuan untuk mengetahui pengaruh variabel independen, yaitu Current Ratio $\left(\mathrm{X}_{1}\right)$ dan Debt to Assets Ratio $\left(\mathrm{X}_{2}\right)$ secara bersama-sama terhadap variabel dependen, yaitu Net Profit Margin (Y).

c. Uji Determinasi

MenurutSugiyono (2015:231)“dalam analisis korelasi terdapat suatu angka yang disebut dengan koefisien determinasi, yang besarnya adalah kuadrat dari koefisien korelasi $\left(\mathrm{r}^{2}\right)$ ".

\section{HASIL PENELITIAN DAN PEMBAHASAN}

\section{A. Uji Asumsi Klasik}

Hasil uji asumsi klasik bertujuan untuk menguji asumsi-asumsi yang disyaratkan dalam menganalisis regresi berganda untuk mengetahui kriteria.

\section{Uji Normalitas}

Uji normalitas bertujuan untuk menguji apakah model regresi, variabel dependen dan independen mempunyai distribusi normal atau tidak. Pengujian normalitas ini secara praktis dapat dilakukan melalui pembuatan grafik normal probability plot.

Grafik dapat dilihat seperti gambar berikut ini :

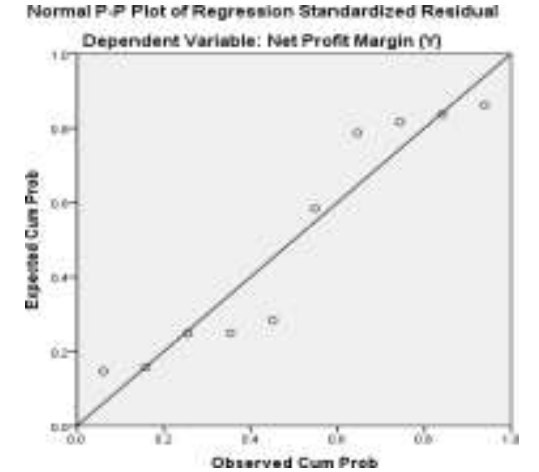

Gambar 4.5

Hasil Uji Normalitas-Normal Probability Plot

Berdasarkan gambar 4.5 grafik P-Plot di atas, terlihat bahwa titik- titik menyebar pada garis diagonal, serta penyebarannya mengikuti arah garis diagonal. Maka dapat dikategorikan model regresi yang di uji adalah layak dipakai untuk penelitian.

Pengujian normalitas menggunakan uji normal Kolmogorov-Smirnov (K-S). hasil pengujian disajikan sebagai berikut :

Tabel 4.5

Hasil Uji Normalitas - Uji

Kolmogorov Smirnov

One-Sample Kolmogorov-Smirnov Test

\begin{tabular}{|ll|l|}
\hline & & \multicolumn{1}{|c|}{$\begin{array}{l}\text { Unstandardize } \\
\mathrm{d} \\
\text { Residual }\end{array}$} \\
\hline $\mathrm{N}$ & & 10 \\
Normal & Mean & .0000000 \\
Parameters & Std. & 2.91990616 \\
a,b & Deviation & \\
Most & Absolute & .242 \\
Extreme & Positive & .242 \\
Difference & Negative & -.217 \\
s & & .242 \\
Test & & \\
Statistic & & \\
Asymp. Sig. (2-tailed) & $.101^{\mathrm{c}}$ \\
\hline
\end{tabular}

Sumber : Data diolah menggunakan SPSS 22

Berdasarkan tabel 4.5 One-Sampel 
Kolmogorov-Smirnov di atas, dapat melihat nilai Asymp. Sig. (2-tailed) sebesar 0,101lebih besar dari 0,05. Syarat lulus uji normalitasa adalah nilai Asymp. Sig. (2-tailed)>0,05 $(0,101>0,05)$. Melalui hasil uji normalitas yang dilakukan, maka dengan demikian secara keseluruhan dapat disimpulkan bahwa nilai-nilai observasi data telah berdistribusi secara normal dan dapat dilanjutkan dengan uji asumsi klasik lainnya.

\section{Uji Multikolinearitas}

Multikolinearitas dapat juga dilihat dari nilai Tolerance dan lawannya Variance Inflation Factor (VIF). Kedua ukuran ini menunjukkan setiap variabel bebas manakah yang dijelaskan oleh variabel bebas lainnya. Tolerance mengukur variabilitas variabel bebas yang terpilih yang tidak dapat dijelaskan oleh variabel bebas lainnya. Jadi nilai Tolerance rendah sama dengan nilai VIF tinggi (karena VIF-1/tolerance) dan menunjukkan adanya kolinearitas yang tinggi. Nilai cutoffyang umum dipakai adalah nilai tolerance di atas 0,10 atau sama dengan nilai VIF di bawah 10. Adapun hasil uji Multikolinearitas dengan SPSS 22 tersaji dalam Tabel 4.6berikut :

Tabel 4.6

Hasil Uji Multikolinearitas

Coefficients $^{\mathrm{a}}$

\begin{tabular}{|ll|l|l|}
\hline \multicolumn{2}{|c|}{$\begin{array}{l}\text { Mode } \\
1\end{array}$} & \multicolumn{2}{|c|}{ Collinearity Statistics } \\
\cline { 2 - 4 } & Tolerance & VIF \\
\hline 1 & Current & .723 & 1.384 \\
& Ratio (X1) & & \\
Debt to & .723 & 1.384 \\
Assets Ratio & & \\
(X2) & & \\
\hline
\end{tabular}

a. Dependent Variable: Net Profit Margin (Y)

Sumber : Data diolah menggunakan SPSS 22

Dari tabel Coefficients

yang diperoleh, dapat diketahui bahwa nilai tolerance Current Ratio dan Debt to Asset Ratio sebesar 0,723 dan nilai VIF untuk Current Ratio dan Debt to Asset Ratio sebesar 1,384. Artinya, nilai VIF lebih kecil < 10. Dengan demikian, dapat disimpulkan bahwa tidak terjadi gejala multikolinearitas di antara variabel bebas.

\section{Uji Heteroskedastisitas}

Uji heteroskedastisitas bertujuan untuk menguji apakah dalam model regresi terjadi ketidaksamaan varian dari residual satu pengamatan ke pengamatan yang lain. Jika varian dari residual satu pengamatan ke pengamatan yang lain tetap, maka disebut homoskedastisitas dan jika berbeda akan disebut heteroskedastisitas.

Untuk melakukan pengujian heteroskedastisitas adalah dengan melihat gambar di bawah ini :

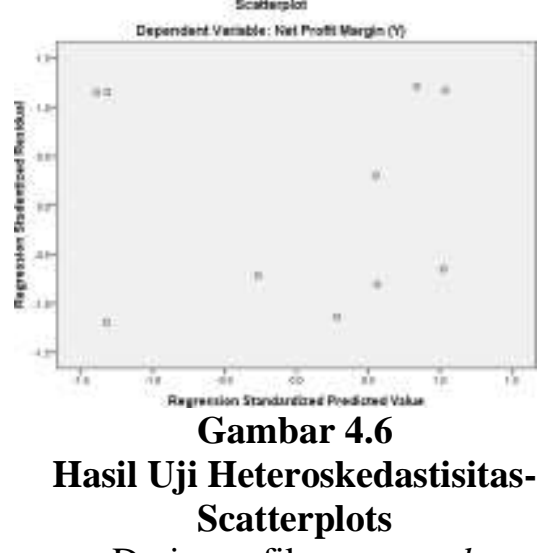

Dari grafik scatterplots pada gambar 4.6 terlihat bahwa titik - titik menyebar secara acak serta tersebar baik di atas maupun di bawah angka 0 pada sumbu Y. Hal ini dapat disimpulkan bahwa tidak terjadi heteroskedastisitas pada model regresi, sehingga model regresi layak digunakan untuk penelitian.

\section{Uji Autokorelasi}

Uji autokorelasi yang digunakan untuk menguji apakah model regresi ada korelasi antara residual pada periode $\mathrm{t}$ dengan residual pada periode sebelumnya $\mathrm{t}-1$. Model pengujian yang digunakan adalah uji statistikRuns Test pada tabel berikut ini :

Tabel 4.7

Hasil Uji Autokorelasi dengan Runs Test Runs Test 


\begin{tabular}{|l|l|}
\hline & $\begin{array}{l}\text { Unstandardized } \\
\text { Residual }\end{array}$ \\
\hline Test Value & a \\
Cases $<$ Test Value & -.59682 \\
Cases $>=$ Test Value & 5 \\
Total Cases & 10 \\
Number of Runs & 8 \\
Z & 1.006 \\
Asymp. Sig. (2-tailed) & .314 \\
\hline
\end{tabular}

a. Median

Sumber : Data diolah menggunakan SPSS 22

Syarat uji Runs Test dikatakan lolos apabila nilai Asymp. Sig. (2tailed) $>0,05$. Berdasarkan hasil uji Runs Test di atas nilai Asymp. Sig. (2tailed) sebesar 0,314 yang artinya memiliki nilai lebih besar dari 0,05 . Maka dari itu, dalam penelitian ini tidak terjadi autokorelasi.

\section{B. Analisis Regresi Linear Berganda}

Pada penelitian ini teknis analisis data yang digunakan adalah regresi berganda. Teknis analisis ini digunakan untuk mengetahui besarnya pengaruh Current Ratio (CR) dan Debt to Assets Ratio (DAR) terhadap Net Profit Margin (NPM) dengan pengolahan SPSS versi 22, maka didapat hasil regresi sebagai berikut :

Tabel 4.8

Hasil Analisis Regresi Linear Berganda Coefficients ${ }^{\mathbf{a}}$

\begin{tabular}{|c|c|c|c|c|c|}
\hline \multirow[t]{2}{*}{ Model } & \multicolumn{2}{|c|}{$\begin{array}{l}\text { Unstandardi } \\
\text { zed } \\
\text { Coefficient } \\
\text { s }\end{array}$} & $\begin{array}{l}\text { Stand } \\
\text { ar } \\
\text { dized } \\
\text { Coeff } \\
\text { ic } \\
\text { ients }\end{array}$ & $\mathrm{t}$ & Sig. \\
\hline & B & $\begin{array}{l}\text { Std } \\
\dot{\text { Err }} \\
\text { or }\end{array}$ & Beta & & \\
\hline $\begin{array}{l}\text { (Cons } \\
\text { ta nt) } \\
\text { Curre } \\
\text { nt } \\
\text { Ratio } \\
\text { (X1) }\end{array}$ & $\begin{array}{l}69.189 \\
.148\end{array}$ & $\begin{array}{l}17.573 \\
.040\end{array}$ & .803 & $\begin{array}{l}-3.937 \\
3.718\end{array}$ & .007 \\
\hline
\end{tabular}

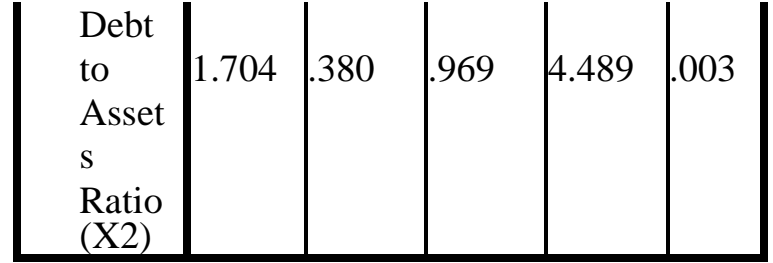

a. Dependent Variable: Net Profit Margin (Y) Sumber : Data diolah menggunakan SPSS 22

Dari tabel coefficients di atas maka diperoleh persamaan regresi sebagai berikut :

$$
Y=-69,189+0,148 X_{1}+1,704 X_{2}
$$

C. Koefisien Korelasi

Koefisien korelasi ini menunjukkan kekuatan hubungan antara semua variabel bebas dan variabel terikat yang berfungsi untuk mengukur derajat linier antara Current Ratio dan Debt to Assets Ratio secara simultan (bersama-sama) terhadap Net Profit Margin, disajikan pada tabel sebagai berikut :

Tabel 4.9

Hasil Analisis Korelasi Model Summary ${ }^{\text {b }}$

\begin{tabular}{|l|l|l|c|c|}
\hline $\begin{array}{l}\text { Mode } \\
1\end{array}$ & $\mathrm{R}$ & $\begin{array}{l}\mathrm{R} \\
\text { Squar } \\
\mathrm{e}\end{array}$ & $\begin{array}{l}\text { Adjuste } \\
\mathrm{d} \quad \mathrm{R} \\
\text { Square }\end{array}$ & $\begin{array}{l}\text { Std. } \\
\text { Error } \\
\text { of the } \\
\text { Estimate }\end{array}$ \\
\hline 1 & .874 & .764 & .697 & 3.31086 \\
\hline
\end{tabular}

a. Predictors: (Constant), Debt to Assets Ratio (X2), Current Ratio (X1)

b. Dependent Variable: Net Profit Margin (Y)

Sumber : Data diolah menggunakan SPSS 22

Dari kolom keluaran SPSS di atas yaitu tabel model summary, terlihat bahwa angka $\mathrm{R}$ atau nilai koefisien korelasi berganda atau simultan sebesar 0,874. Nilai ini menunjukkan bahwa hubungan yang terjadi antara perubahan semua variabel bebas dengan variabel terikat adalah sangat kuat sekali.

D. Uji Hipotesis

\section{Uji Parsial (Uji T)}

Uji t bertujuan untuk mengetahui 
pengaruh variabel independen yang terdiri dari Current Ratio(CR)dan Debt to Assets Ratio(DAR)terhadap Net Profit Margin(NPM)pada PT Indo Tambangraya Megah TBK secara parsial.

Tabel 4.10

Hasil Pengujian Uji T Coefficients $^{\mathrm{a}}$

\begin{tabular}{|c|c|c|c|c|c|}
\hline \multirow[t]{2}{*}{ Model } & \multicolumn{2}{|c|}{$\begin{array}{l}\text { Unstandard } \\
\text { ized } \\
\text { Coefficient } \\
\text { s }\end{array}$} & \multirow{2}{*}{\begin{tabular}{|l}
$\begin{array}{l}\text { Standa } \\
\text { rdized } \\
\text { Coeffi } \\
\text { cients }\end{array}$ \\
Beta
\end{tabular}} & \multirow[t]{2}{*}{$\mathrm{t}$} & \multirow[t]{2}{*}{ Sig } \\
\hline & B & $\begin{array}{l}\text { Std. } \\
\text { Error }\end{array}$ & & & \\
\hline (Constant) & $\begin{array}{l}- \\
69.1 \\
89\end{array}$ & $\begin{array}{l}17.5 \\
73\end{array}$ & & $\begin{array}{l}- \\
3.9 \\
37\end{array}$ & $\begin{array}{l}.00 \\
6\end{array}$ \\
\hline $\begin{array}{l}\text { Current } \\
\text { Ratio (X1) }\end{array}$ & .148 & .040 & .803 & $\begin{array}{l}3.7 \\
18\end{array}$ & $\begin{array}{l}.00 \\
7\end{array}$ \\
\hline $\begin{array}{l}\text { Debt to } \\
\text { Assets Ratio } \\
\text { (X2) }\end{array}$ & $\begin{array}{l}1.70 \\
4\end{array}$ & .380 & .969 & $\begin{array}{l}4.4 \\
89\end{array}$ & $\begin{array}{l}.00 \\
3\end{array}$ \\
\hline
\end{tabular}

a. Dependent Variable: Net Profit Margin (Y) Sumber : Data diolah menggunakan SPSS 22

Berdasarkan tabel 4.10 di atas pada variabel Current Ratio di atas diperoleh nilai $t_{\text {hitung }}$ sebesar 3,718 $>\mathrm{t}_{\text {tabel }}$ sebesar2,365 sehingga jatuh pada daerah penerimaan $\mathrm{H}_{\mathrm{o}}$ maka $\mathrm{H}_{\mathrm{o}}$ ditolak $\mathrm{H}_{a}$ diterima. Serta dilihat pada tabel 4.10 di atas dapat dilihat pula besar angka signifikansi yaitu 0,007 yang berarti angka ini lebih kecil dari tingkat signifikansi $(0,007<0,05)$, maka dapat ditarik kesimpulan bahwa perubahan Current Ratio secara parsial berpengaruh signifikan terhadap Net Profit Margin.

Selanjutnya berdasarkan tabel 4.10 di atas pada tabel Debt to Assets Ratio diperoleh nilai $t_{\text {hitung }}$ sebesar 4,489dengan tingkat signifikansi 0,05 dan derajat kebebasan $(\mathrm{dk}) \mathrm{n}-\mathrm{k}-1=10-2-1$ $=7$ adalah sebesar 2,365. Dengan melakukan perbandingan yaitu $t_{\text {hitung }}$ sebesar 4,489> $t_{\text {tabel }}$ sebesar2,365, sehingga jatuh pada daerah penerimaan $\mathrm{H}_{\mathrm{o}}$ maka $\mathrm{H}_{\mathrm{o}}$ ditolak $\mathrm{H}_{\mathrm{a}}$ diterima. Serta dilihat pada tabel 4.10 di atas dapat dilihat pula besar angka signifikansi yaitu 0,003 yang berarti angka ini lebih kecil dari tingkat signifikansi $(0,003<0,05)$, maka dapat ditarik kesimpulan bahwa perubahan Debt to Assets Ratio secara parsial berpengaruh signifikan terhadap Net Profit Margin.

\section{Uji Simultan (Uji F)}

Uji $\mathrm{F}$ digunakan untuk menguji pengaruh variabel independen yaitu Current Ratio dan Debt to Assets Ratio secara simultan terhadap Net Profit Margin, yaitu dengan membandingkan antara nilai $\mathrm{F}_{\text {hitung }}$ dengan $\mathrm{F}_{\text {tabel. }}$

Berikut perhitungan uji hipotesis yang menggunakan uji signifikansi dengan pengujian menggunakan uji $\mathrm{F}$ dihitung melalui alat software program SPSS versi 22 :

Tabel 4.11

Hasil Pengujian Uji F ANOVA $^{a}$

\begin{tabular}{|l|l|l|l|l|l|}
\hline Model & $\begin{array}{l}\text { Sum of } \\
\text { Square } \\
\text { s }\end{array}$ & Df & $\begin{array}{l}\text { Mean } \\
\text { Square }\end{array}$ & F & Sig. \\
\hline $\begin{array}{l}\text { Regres } \\
\text { sion }\end{array}$ & $\begin{array}{l}248.67 \\
\text { Residu } \\
\text { al } \\
\text { Total }\end{array}$ & 2 & 124.339 & $\begin{array}{l}11.3 \\
43\end{array}$ & $.006^{\mathrm{b}}$ \\
& $\begin{array}{l}325.433 \\
1\end{array}$ & 7 & 10.962 & & \\
\hline
\end{tabular}

a. Dependent Variable: Net Profit Margin (Y)

b. Predictors: (Constant), Debt to Assets Ratio (X2), Current Ratio (X1)

Sumber : Data diolah menggunakan SPSS 22

Berdasarkan hasil pengujian Analysis of Variance (ANOVA) di atas diperoleh nilai $\mathrm{F}_{\text {hitung }}$ sebesar 11,343 dengan signifikansi 0,006 sedangkan pada $\mathrm{F}_{\text {tabel }}$ dengan signifikansi $0,05 \mathrm{~d} f 1$ $=\mathrm{k}=2, \mathrm{~d} f 2=\mathrm{n}-\mathrm{k}-1=10-2-1=$ 7, diperoleh $F_{\text {tabel }}$ sebesar 4,74. Dengan kondisi ini dimana $F_{\text {hitung }}$ lebih besar dari pada $\mathrm{F}_{\text {tabel }}(11,343>4,74)$ dan nilai signifikan lebih kecil dari $\alpha=0,05$ $(0,006<0,05)$, maka dapat diambil kesimpulan adalah $\mathrm{H}_{\mathrm{o}}$ ditolak dan $\mathrm{H}_{\mathrm{a}}$ diterima yang berarti Current Ratio dan 
Debt to Assets Ratio berpengaruh signifikan secara simultan terhadap Net Profit Margin.

\section{Uji Koefisien Determinasi}

Melalui pengujian simultan dapat diketahui besarnya koefisien determinasi R Square. Dari koefisien determinasi $\mathrm{R}$ Square dapat diketahui derajat ketepatan dari analisis regresi linier berganda menunjukkan besarnya variasi sumbangan seluruh variabel bebas terhadap variabel terikatnya. Hasil koefisien determinasi penelitian ini dapat terlihat pada tabel 4.12 sebagai berikut :

Tabel 4.12

Hasil Koefisien Determinasi Model Summary ${ }^{b}$

\begin{tabular}{|l|l|l|l|l|}
\hline $\begin{array}{l}\text { Mode } \\
1\end{array}$ & $\mathrm{R}$ & $\begin{array}{l}\mathrm{R} \\
\text { Square }\end{array}$ & $\begin{array}{l}\text { Adjusted } \\
\mathrm{R} \text { Square }\end{array}$ & $\begin{array}{l}\text { Std. Error } \\
\text { of the } \\
\text { Estimate }\end{array}$ \\
\hline 1 & $.874^{\mathrm{a}}$ & .764 & .697 & 3.31086 \\
\hline
\end{tabular}

a. Predictors: (Constant), Debt to Assets Ratio (X2), Current Ratio (X1)

b. Dependent Variable: Net Profit Margin (Y)

Sumber : Data diolah menggunakan SPSS 22

Berdasarkan tabel model summary besarnya nilai pengaruh variabel bebas ditunjukkan oleh nilai $\mathrm{R}^{2}=0,764$ maka $\left(\mathrm{KD}=\mathrm{r}^{2} \times 100 \%=\right.$ $0,764 \times 100 \%=76,4 \%$ ) jadi dapat disimpulkan bahwa Current Ratio dan Debt to Assets Ratio berpengaruh sebesar 76,4\% terhadap Net Profit Margin, sedangkan 23,6\% dipengaruhi oleh variabel lain yang tidak diteliti di dalam penelitian ini.

\section{E. Pembahasan Hasil Penelitian}

\section{Pengaruh Current Ratio Terhadap Net Profit Margin}

Berdasarkan hasil uji statistik koefisien regresi, regresi Current Ratio sebesar 0,148 artinya apabila Current Ratio mengalami kenaikan, sedangkan variabel lain (Debt to Asset Ratio) dianggap konstan atau tidak mengalami perubahan, maka Net Profit Margin akan meningkat sebesar $0,148 \%$. Hasil pengujian hipotesis menunjukkan Current Ratio berpengaruh positif pada PT Indo Tambangraya Megah TBK. Diperoleh $\mathrm{t}_{\text {hitung }}$ untuk variabel Current Ratio $\left(\mathrm{X}_{1}\right)$ sebesar 3,718 dengan nilai $\mathrm{t}_{\text {tabel }}$ sebesar 2,365, ini menunjukkan bahwa Current Ratio berpengaruh terhadap Net Profit Margin. Hal ini dapat dilihat dari nilai-nilai $t_{\text {hitung }}$ lebih besar dari pada $t_{\text {tabel }}$ atau sebesar 3,718 $>2,365$ dan nilai signifikan level $0,007<0,05$. Maka $\mathrm{H}_{\mathrm{o}}$ ditolak $\mathrm{H}_{\mathrm{a}}$ diterima, dapat disimpulkan bahwa secara parsial Current Ratio berpengaruh positif dan signifikan terhadap Net Profit Margin.

Penelitian ini menyatakan bahwa secara parsial Current Ratio berpengaruh positif terhadap Net Profit Margin. Artinya, semakin tinggi Current Ratio yang digunakan maka Net Profit Margin perusahaan semakin naik, hal ini dikarenakan PT Indo Tambangraya Megah TBK telah memenuhi hutang lancar dengan menggunakan aktiva lancar yang dimiliki perusahaan.

\section{Pengaruh Debt to Assets Ratio} terhadap Net Profit Margin

Berdasarkan hasil uji statistik koefisien regresi, regresi Debt to Asset Ratio sebesar 1,704 artinya apabila Debt to Asset Ratio mengalami kenaikan, sedangkan variabel lain (Current Ratio) dianggap konstan atau tidak mengalami perubahan, maka Net Profit Margin akan meningkat sebesar 1,704\%. Hasil pengujian hipotesis menunjukkan hasil perhitungan $\mathrm{t}_{\text {hitung }}$ untuk variabel Debt to Asset Ratio $\left(\mathrm{X}_{2}\right)$ sebesar 4,489 dengan nilai $t_{\text {tabel }}$ sebesar 2,365, ini menunjukkan bahwa Debt to Asset Ratio berpengaruh positif dengan signifikan 0,003 lebih kecil dari tarafsignifikan 0,05. Maka $\mathrm{H}_{\mathrm{o}}$ ditolak $\mathrm{H}_{\mathrm{a}}$ diterima, dapat disimpulkan bahwa secara parsial Debt to Asset Ratio berpengaruh positif dan signifikan terhadap Net Profit Margin.

Penelitian ini menyatakan bahwa 
secara parsial Debt to Asset Ratio berpengaruh positif terhadap Net Profit Margin. Artinya, semakin tinggi Debt to Asset Ratio yang digunakan dalam proses kegiatan operasional maka Net Profit Margin perusahaan semakin meningkat, hal ini dikarenakan PT Indo Tambangraya Megah TBK telah maksimal dalam pengelolaan Debt to Asset Ratio untuk meningkatkan Net Profit Margin.

3. Pengaruh Current Ratio dan Debt to Assets Ratio terhadap Net Profit Margin

Dari hasil uji $\mathrm{F}$ menunjukkan bahwa nilai $F_{\text {hitung }}$ adalah 11,343 dengan taraf nilai signifikansi sebesar 0,006 . Dengan demikian nilai $F_{\text {hitung }}$ sebesar $11,343>\mathrm{F}_{\text {tabel }}$ sebesar 4,74 dengan taraf signifikansi $(0,006)<(0,05)$, sehingga jatuh pada daerah penerimaan $\mathrm{H}_{\mathrm{O}}$ ditolak $\mathrm{H}_{\mathrm{a}}$ diterima. Dengan demikian ditarik kesimpulan bahwa terdapat pengaruh Current Ratio dan Debt to Assets Ratio secara simultan terhadap Net Profit Margin PT Indo Tambangraya Megah TBK periode 2008-2017.

Kemudian besarnya hasil analisis data yang diperoleh dari nilai $\mathrm{R}^{2}(R$ Square) adalah 0,764 , yang menunjukkan bahwa sebesar $76,4 \%$ pengaruh perubahan Net Profit Margin dapat dijelaskan oleh variabel Current Ratio dan Debt to Assets Ratio, sedangkan 23,6\% dipengaruhi oleh variabel lain yang tidak diteliti di dalam penelitian ini.

\section{KESIMPULAN DAN SARAN}

A. Kesimpulan Penelitian

1. Variabel Current Ratio memiliki thitung sebesar 3,718 dengan nilai signifikansi sebesar 0,007. Dan dapat disimpulkan bahwa $0,007<0,05$ maka Ho ditolak dan Ha diterima, artinya hasil dalam penelitian ini menunjukkan bahwa Current Ratio berpengaruh terhadap Net Profit Margin. Artinya $t_{\text {hitung }}$ dengan tanda positif, menunjukkan jika Current Ratio naik maka Net Profit Margin naik atau sebaliknya jika Current Ratio turun maka Net Profit Margin turun.

2. Variabel Debt to Assets Ratio memiliki $t_{\text {hitung }}$ sebesar 4,489 dengan nilai signifikansi sebesar 0,003 . Dan dapat disimpulkan bahwa $0,003<0,05$ maka Ho ditolak dan Ha diterima, artinya hasil dalam penelitian ini menunjukkan bahwa Debt to Assets Ratio berpengaruh positif dan signifikan terhadap Net Profit Margin. Artinya $\mathrm{t}_{\text {hitung }}$ dengan tanda positif, menunjukkan jika Debt to Assets Ratio naik maka Net Profit Margin naik atau sebaliknya jika Debt to Assets Ratio turun maka Net Profit Margin turun.

3. Berdasarkan hasil perhitungan dengan menggunakan program SPSS 22, diperoleh nilai $\mathrm{F}_{\text {hitung }}$ sebesar 11,343 dan tingkat signifikan sebesar 0,006. Dan dapat disimpulkan bahwa $0,006<0,05$ maka Ho ditolak dan Ha diterima, artinya Current Ratio dan Debt to Assets Ratio terhadap Net Profit Margin secara bersama-sama atau simultan berpengaruh positif dan signifikan terhadap Net Profit Margin.

\section{B. Saran}

1. PT Indo Tambangraya Megah TBK sebaiknya menjaga agar nilai Current Ratio dalam keadaan yang seimbang, tidak terlalu tinggi dan tidak terlalu rendah dan perlu mengalokasikan aktiva lancarnya untuk kegiatan usaha yang lebih baik lagi. Karena dengan nilai Current Ratio yang tinggi, ini mengidentifikasikan banyaknya jumlah aktiva lancar yang menganggur, namun jika Current Ratio yang terlalu rendah mengidentifikasikan bahwa kemampuan perusahaan dalam menjamin hutang lancar dengan aktiva lancar kurang baik. Hal ini yang menyebabkan rasio Current Ratio berpengaruh signifikan terhadap Net Profit Margin, dimana rasio Current Ratio PT Indo 
Tambangraya Megah TBK terlalu tinggi, sehingga banyak aktiva lancar yang menganggur. Padahal jika dikelola dengan baik tentunya aktiva lancar ini mampu memberikan laba bagi perusahaan yang jauh lebih baik.

2. PT Indo Tambangraya Megah TBK sebaiknya menjaga agar nilai Debt to Assets Ratio agar tetap rendah, karena apabila nilai Debt to Assets Ratio tinggi, mengidentifikasikan semakin tingginya tingkat hutang yang dijamin aset perusahaan. Jika rasio Debt to Assets Ratio tinggi, dikhawatirkan akan mengganggu setiap bisnis perusahaan karena banyak kegiatan usaha yang harus dibiayai oleh aset.

3. Terjadinya fluktuatif rasio Net Profit Margin pada PT Indo Tambangraya Megah TBK merupakan efek yang kurang baik untuk perusahaan, sehingga harus menjadi perhatia $\mathrm{n}$ perusahaan pada tingkat Current Ratio dan Debt to Assets, agar perusahaan tidak mengalami kesulitan dalam melunasi hutang jangka pendek maupun hutang jangka panjang dengan laba bersih yang dimiliki perusahaan.

\section{DAFTAR PUSTAKA}

\section{Buku :}

Ghozali, Imam."Aplikasi Analisis Multivarial dengan Program SPSS". Badan Penerbit Universitas Dipenorogo. Semarang. 2016.

Hanafi, Mamduh. "Manajemen". Edisi Kedua, Cetakan Pertama. Universitas Terbuka. Tangerang Selatan. 2015.

Hasibuan, Melayu. "Manajemen: Dasar, Pengertian dan Masalah”. Edisi Revisi, Cetakan Kesembilan. Bumi Aksara. Jakarta. 2011.

Hery. "Analisis Laporan Keuangan".PT. Grasindo. Jakarta. 2016.
Priyanto, Duwi. "Teknik Mudah dan Cepat Melakukan Analisis Data Penelitian dengan SPSS dan Tanya Jawab Ujian Pendadaran”. Gaya Media. Yogyakarta. 2013.

Priyanto, Duwi. "Panduan Praktis Olah Data SPSS". Edisi Kesatu, ANDI. Yogyakarta. 2017.

Ramli, Rusli., dan Yuniati Putri Koes Hardini. “Asas-asas Manajemen”. Edisi Kesatu, Cetakan Kesebelas. Universitas Terbuka. Tangerang Selatan. 2017.

Sartono, Agus. "Manajemen Keuangan: Teori dan Aplikasi”. Edisi Keempat.

2015 .

BPFEYOGYAKARTA. Yogyakarta.

Sugiyono. "Metode Penelitian Bisnis: Pendekatan Kuantitatif, Kualitatif danR\&D”. Alfabeta. Bandung. 2012.

Sugiyono. "Statistika Nonparametris Untuk Penelitian”, Alfabeta. Bandung. 2015.

Sugiyono. "Metode Penelitian Manajemen". Alfabeta. Bandung. 2015.

Sugiyono. "Statistika Untuk Penelitian". Alfabeta. Bandung. 2017.

Sutrisno. "Manajemen Keuangan: Teori Konsep dan Aplikasi". Edisi Pertama, Cetakan Kesembilan. Ekonisia. Yogyakarta. 2013.

Widodo. "Metodologi Penelitian: Populer \& Praktis”. Rajawali Pers. 2017.

Jurnal :

Afriyanti, Ayu. "Pengaruh Current Ratio (CR) dan Debt to Equity Ratio (DER) Terhadap Net Profit Margin (NPM) Pada PT. Kalbe Farma, Tbk". Ekonomi.Universitas Pamulang. 
Tangerang Selatan. 2018.

Agustin, Anisa. "Pengaruh Current Ratio dan Debt to Assets Ratio Terhadap Net Profit Margin pada PT. Ace Hardware Indonesia, Tbk Tahun 2012-2016". Ekonomi. Universitas Pamulang. Tangerang Selatan. 2018.

Erlina, Lisna Eka. "Pengaruh Debt to Assets Ratio dan Debt to Equity Ratio terhadap Gross Profit Margin pada PT. Hm Sampoerna, Tbk Periode Tahun 20092015”. Ekonomi. Universitas Pamulang. Tangerang Selatan. 2016.

Errossa, Pitria Liza. "Pengaruh Current Ratio dan Total Debt to Total Assets Ratio terhadap Net Profit Margin pada perusahaan Food And Beverage yang terdaftar di Bursa Efek Indonesia Periode 2008-2012”. Bisnis dan Manajemen. Universitas Widyatama. Bandung. 2013.

Suharjo. "Pengaruh Return On Assets (ROA),Current Ratio (CR), Net Profit Margin (NPM) dan Inflasi Terhadap Harga Saham Pada PT. Kalbe Farma, Tbk Periode Tahun 2001-2014". Jurnal Maksipreneur, Volume IV, Nomor 02 : 1-65. 2015.

Oktrima, B. (2017). Pengaruh Profitabilitas, Likuiditas, Dan Struktur Modal Terhadap Nilai Perusahaan. Open Journal. Universitas Pamulang.

Oktrima, B., \& Riani, N. (2019). PENGARUH PERPUTARAN KAS DAN PERPUTARAN PIUTANG TERHADAP RETURN ON INVESTMENT (ROI) PADA PT. SEMEN INDONESIA (PERSERO) TBK PERIODE TAHUN 20082017. Jurnal Ekonomi Efektif, 2(1).
Oktrima, B. (2018). ANALISIS KINERJA KEUANGAN MENGGUNAKAN RASIO PROFITASBILITAS DAN LIKUIDITAS PADA PT. RAMAYANA LESTARI SENTOSA, TBK. Jurnal Ekonomi Efektif, 1(1).

Purnomo, S., \& Pasaribu, V. L. D. (2019). PERGERAKAN HARGA SAHAM PT ADARO ENERGY TBK (ADRO) PADA PENGUMUMAN DIVIDEN INTERIM TAHUN BUKU 2018. Jurnal Ekonomi Efektif, 2(1).

Wihyahya. "Pengaruh Current Ratio dan Cash Ratio Terhadap Net Profit Margin Pada PT. Jaya Real Property, Tbk. Dan Entitas Anak 2008-2012'.Jurnal FinAcc STIE Widya Dharma Pontianak, Volume 01, Nomor 04 : 748, 2016.

\section{Website :}

www. Itmg.co.id www.idx.co.id 